Jinlan Tang*, Kan Qian, Na Wang and Xiaona Hu

\title{
Exploring language learning and corrective feedback in an eTandem project
}

https://doi.org/10.1515/jccall-2021-2005

Received April 10, 2021; accepted July 10, 2021; published online September 3, 2021

\begin{abstract}
Many studies about eTandem and language learning stem from learners in Western institutions of higher education. Unfortunately, there is a lack of research investigating the telecollaboration regarding language development between learners in the East and the West. Against this backdrop, a small-scale, sixweek Chinese-English eTandem project focusing on learners' language learning processes and experiences was undertaken between nine Chinese university students learning English in China and nine British university students learning Chinese in the UK. Multiple datasets were collected from learners' diaries, synchronous Skype communication recordings, email exchanges, interviews and a post-project survey. This paper reports the main language error types made by Chinese L2 learners of English and error correction strategies provided by eTandem partners of competent L1 English speakers, along with how Chinese participants responded to the corrections. A thorough analysis of the research data indicated three types of linguistic errors in written tasks made by Chinese L2 learners of English: grammatical, lexical and idiomatic expressions. Another finding was that, although explicit written correction was the most commonly used strategy in email exchanges, learners preferred explanations with examples. In addition to previously established gains of eTandem learning, such as authentic communication, forging friendship and promoting intercultural awareness, positive responses to competent L1 partners' error corrections was another major benefit indicated in our data. Our study pinpoints the importance of both pre-project training of participants on error-correction strategies with examples and how to respond to partner feedback in future eTandem projects.
\end{abstract}

Keywords: error correction; error response; eTandem language learning; feedback; telecollaboration

\footnotetext{
*Corresponding author: Jinlan Tang, Beijing Foreign Studies University, Beijing, China, E-mail: tangjinlan@bfsu.edu.cn

Kan Qian, The Open University, Milton Keynes, UK, E-mail: qian.kan@open.ac.uk Na Wang and Xiaona Hu, Beijing Foreign Studies University, Beijing, China, E-mail: wangna@beiwaionline.com (N.Wang), huxiaona@beiwaionline.com (X. Hu) 


\section{Introduction}

Tandem language learning is a method of language learning based on mutual language exchange between partners, where ideally each learner is a native speaker in the language the other person wants to learn. Tandem language learning is essentially peer learning because the tandem partners are encouraged to take on the role of peer tutor to "provide feedback on their partners' foreign language performance, correct errors and offer new formulations” (Helm, 2015, p. 198). With the rapid development of the Internet and mobile technologies, online tandems-eTandems or teletandems-involving emails, online synchronous chats, asynchronous forums and videoconferencing have become increasingly popular. Arguably, no matter what form the tandem approach might assume, the two basic principles of tandem, that is, reciprocity and autonomy, remain unchanged (Giguère \& Parks, 2018).

With a large English language learning population in China, one of the main challenges in foreign language education programs is the lack of target language environment and opportunities to communicate with competent English speakers about real-life matters. Thanks to technological advances, such virtual opportunities in the form of eTandem learning have become a reality. This is helped by the increasing demand for Chinese language learning in the world (British Council, 2018; Duff et al., 2013). Many western learners of Putonghua are keen to communicate with speakers of the language in China. However, the recent systematic literature reviews on telecollaborative learning have identified a gap: studies on eTandem learning so far involve fewer countries (Barbosa \& Ferreira-Lopes, 2021), such as between L2 learners of English in China and L2 learners of Chinese in other countries (Jin, 2013; Luo \& Yang, 2018).

Our study intends to fill the gap by exploring how these two groups of learners collaborate in meaningful virtual exchanges to improve their L2 proficiency. The findings of the study may help to expand telecollaborative learning networks called for by Barbosa and Ferreira-Lopes (2021). Our focus is on corrective feedback in eTandem learning because findings from second language acquisition (SLA) studies have shown that corrective feedback on L2 errors is beneficial to language learning (e.g., Ellis, 2007; Vinagre \& Lera, 2008). It is hoped that through identifying L2 error types made by the Chinese L2 learners of English along with L1 feedback strategies by their competent L1 partners, in addition to how Chinese L2 participants responded to the feedback, we will achieve a better understanding of their language development via eTandem learning.

The following section reviews the literature on eTandem learning principles and design as well as corrective feedback and types of errors, thereby providing 
guidelines for our own project design and data analysis. In the methodology section, our data sources and methods of analysis are described. The analyses and results are presented in the findings and discussion section, which focuses, in particular, on error types, corrective feedback strategies and how Chinese L2 participants responded to error feedback from competent L1 partners. The final section offers conclusions with pedagogical implications, limitations of the study and suggestions for future research.

\section{Literature review}

\section{1 eTandem learning: principles, settings and design}

As mentioned in the introduction, the two guiding principles of tandem learning are reciprocity and autonomy. Reciprocity means that approximately half the communication (speaking or written) should be in one language and the other half in another language, with error correction provided by competent L1 speakers for their L2 partners, providing peer support and playing the tutor role. With regard to autonomy, the learners should be able to decide what to talk about and when as well as undertake their own roles (tutors or tutees) in this process, offering and receiving feedback. Adhering to these two principles successfully paves the way for learners to make the most out of the tandem learning opportunities. eTandem learning does the same in online environments using multiple (i.e., textual, aural and visual) communicative modes (Lewis \& Peters, 2019).

The benefits of eTandem learning (also known as telecollaboration, intercultural exchange or virtual exchange) have been well-documented in terms of learner motivation, authentic communication opportunities, building friendship, improving linguistic competence and gaining cultural insights (e.g., Dooly \& O’Dowd, 2018; Kan, Stickler, \& Xu, 2013; Lewis, Chanier, \& Youngs, 2011; Luo \& Yang, 2018; O’Dowd \& O’Rourke, 2019; Rienties, Lewis, O’dowd, Rets, \& Rogaten, 2020). Other benefits include learner confidence and trust because these programmes are organised by teaching institutions, so learners feel it is a safe and educational yet real space (Woodin, 2020). Such a space with two partners' communicating with each other facilitates personalised learning where learners do not have to worry about making mistakes and losing face (Kukulska-Hulme et al., 2021).

It needs to be pointed out that autonomy does not mean that learners do not get support and guidance. A large-scale study examining learners' attitudes, usage and progress in a major Language Learning Social Network Site (LLSNS) conducted by Lin, Warschauer, and Blake (2016) found that learners needed support, 
guidance and well-structured activities to ensure the kinds of participation and linguistic interaction to make learning successful. Moreover, studies have shown that the types of tasks may affect how learners communicate and negotiate feedback in online collaboration (e.g., Lee, 2006; O'Dowd \& Ware, 2009).

It is noted that the majority of the eTandem projects have been between European language learners at the intermediate or advanced language levels (see Hauck \& Youngs, 2008; O’Dowd \& O’Rourke, 2019; Stickler \& Lewis, 2008). The systemic review of telecollaboration in the last 20 years conducted by Luo and Yang (2018) pointed out that this approach of learning had not yet "made its way to the field of Chinese language education or the teaching of other less commonly taught languages" (p. 548). The focus of this review was on telecollaborative practice in teaching Chinese as a foreign language. Our study focuses more on teaching English as a foreign language to adult learners inside China.

There are a few studies in the context of Chinese L2 learners of English in partnership with western L2 learners of Chinese. Kan et al.'s (2013) study focused on attitudes, beliefs and the organisational side, revealing that eTandem learning helped motivate students as the learners used the language for authentic communication and stressed the importance of pre-project preparation. Tian and Wang's (2010) study explored if eTandem via Skype could be a sustainable mode of learning outside the classroom; however, there was no definite conclusion because of differing opinions from participants-further research was needed. A few eTandem learning projects (Wu, 2018; Xiong, 2017; Xue, 2010) in China were between Chinese and US partners, but the focus was mainly on writing performance outcomes. Ren and Liang (2014) studied intercultural communicative competence in their Sino-US eTandem project and reported positive results on students' interaction confidence, interaction enjoyment, intercultural sensitivity and overall intercultural effectiveness. None of these studies, however, investigated language error types, feedback strategies and learners' preferred ways of error correction strategies, all of which play important parts in language learning (e.g., Loewen \& Erlam, 2006; Sáez \& Segovia, 2013) (see below for literature review on corrective feedback).

Due to the language learning potential that telecollaborative exchanges might bring, especially post Covid-19, through corrective feedback from partners (Kessler, 2009; Lee, 2006; Sauro, 2009; Ware \& O’Dowd, 2008), previous researchers have endeavoured to examine the extent to which this practice impacts L2 development (e.g., Lee, 2006; Sauro, 2009), and more so on virtual interaction, and how corrective feedback from L1 speakers may improve the learning process. Below we will review some studies on corrective feedback. 


\subsection{Corrective feedback and the interaction hypothesis}

The theory guiding most studies on how online collaborative interaction enhances the development of learners' language competence is the interaction hypothesis (cf. Long \& Robinson, 1998), which argues that negotiation for meaning elicits interactional modifications and corrective feedback, including explicit correction, recasts and clarification. This helps learners notice gaps in their interlanguage and contribute to their language improvement. Corrective feedback is a focus-on-form procedure, drawing students' attention to linguistic aspects as they appear incidentally in communication (Long, 1991).

The importance of corrective feedback on language learning has been advocated for by previous researchers (e.g., Bartram \& Walton, 1991; Hyland, 2003; Li, 2010; Little \& Ushioda, 1998). For example, it has been argued that 'in naturalistic as well as in formal contexts, feedback is one of the most important stimuli to learning' (Little \& Ushioda, 1998, p. 96). The most important reasons are arguably that corrective feedback raises metalinguistic awareness, and the engagement of correcting errors leads to active learning.

\subsection{Types of errors, feedback strategies and language development}

There is a substantial body of literature on error types and corrective feedback strategies in the field of SLA (e.g., Hyland, 2003; Lyster \& Ranta, 1997; Morris, 2005). Three main types of language errors were identified in Morris' (2005) study: syntactic errors (grammatical), lexical errors and unsolicited L1 use (e.g., instances when learners used L1 when L2 would have been more appropriate and expected). It is worth noting that the recent research on translanguaging advocates for L2 learners to make full use of their linguistic repertoire in meaning-making. $\mathrm{Li}$ (2018) suggested that the actual learning of a new language is not to replace the learner's L1 but to become bilingual and multilingual. So, relying on one's L1 to get one's meaning across is not regarded as incorrect by many scholars (e.g., García, 2009; Li, 2018).

As for feedback types, Lyster and Ranta (1997) proposed that explicit correction and metalinguistic feedback were explicit types, while recasts and clarification requests were among the implicit types of corrective feedback. In Morris' (2005) study, three categories of corrective feedback strategies were used: explicit correction (indicating the error and giving the correct version), recasts (reformulation of an ill-formed utterance) and negotiation of form (signalling for peer and 
self-repair). The majority of lexical and syntactic errors were corrected using negotiation: the main contributing factor was that the participants were young learners who did not have a solid linguistic knowledge and communicative competence for explicit correction or recast strategies.

Studies on language development via the use of corrective feedback in asynchronous exchanges in the form of email, discussion forums and wikis have demonstrated that students prefer the inclusion of focus on form, and that corrective feedback from peers might enhance language learning and reflection. For example, Ware and O'Dowd (2008) discovered that students welcomed feedback on language accuracy in their weekly online asynchronous discussions; the two researchers called for including peer feedback in the current model of telecollaboration and training students to use feedback strategies such as reformulations. The studies also necessitated training students regarding corrective feedback provision strategies (Jin, 2013; Kessler, 2009; Vinagre \& Maíllo, 2007; Ware \& O’Dowd, 2008). However, none of them provided detailed suggestions as to how to implement the training.

In studying a chat-line interaction between two groups of L2 speakers, Iwasaki and Oliver (2003) identified a new error category, typographical, in addition to lexical and grammatical errors identified by Morris (2005). Bower and Kawaguchi (2011) added two more error types, 'pragmatic and idiomatic' (p. 54) during their study, which consisted of a three-session virtual exchange of 21 university students from a first-year general English class in Japan who were paired with 21 university students from a second-year Japanese class in Australia. Each session had guided activities using MSN Messenger, which allowed for text-based instant messaging, voice calls and video conferencing. Participants were also asked to review the synchronous logs of their partners' chat messages and send corrective feedback via email. Three main error correction strategies were identified in the email communication: metalinguistic explanation, reformulation and reformulation with metalinguistic explanation. The research indicated that both groups made more grammatical errors than the other error types, using reformulation the most frequently. It is also interesting to note that the Japanese partners provided nearly double the number of metalinguistic explanations along with reformulations than their counterparts in Australia, which might be linked to the fact that the English language classes in Japan had a strong grammar-translation focus. The study also indicated that age, educational background and social relationship between participants might be important factors mediating the type and amount of corrective feedback provided.

With the aim of discovering what types of error correction can lead to development in language competence, Vinagre and Lera (2008) identified three different types of corrective feedback during a year-long email exchange project 
between learners of English and of Spanish: (1) feedback, indicating errors without correction or explanations; (2) correction; and (3) remediation, offering specific suggestions for revision. Correction was used on lexical and orthographical errors (similar to "typographical" errors as identified by Iwasaki and Oliver in their 2003 study), whilst errors in syntactic structures were dealt with by remediation. It is suggested that remediation, as opposed to correction and feedback, seemed to be more effective in fostering linguistic development.

In a similar study by Vinagre and Muñoz (2011) on the effectiveness of error correction strategies via email exchanges between seventeen post-secondary learners of Spanish and German whose L2 language proficiency was deemed A2 in CEFR, it was discovered that students appeared to use more correction and remediation strategies. In addition, there was some evidence that strategies of explicit correction and remediation fostered development of linguistic accuracy.

There have been few studies investigating learner preference for particular error correction in eTandem learning (Akiyama, 2017; Giguère \& Parks, 2018). Contrary to Morris (2005), Giguère and Parks' (2018) study on a telecollaboration project found that explicit feedback was the preferred strategy rather than negotiation of form. Feedback training for the learners was conceived as one of the main contributing factors. Akiyama (2017) examined students' preferred ways of error correction strategies in a 14-week, Skype-based eTandem project between American and Japanese students. One of the key findings was that students favoured recasts (i.e., paraphrases) above other corrective feedback strategies such as explicit correction, metalinguistic explanation, elicitation, repetition and clarification requests [as identified in Lyster and Ranta's (1997) study] since recasts were regarded as timesaving and unintrusive. Akiyama's (2017) study also indicated a positive relationship between successful uptake and students' preferred ways of receiving corrective feedback. It would be very useful to find out if this finding applies to eTandem projects which involve both synchronous Skype conversations and asynchronous email exchanges.

In summary, as far as we are aware, no studies have been carried out so far on the language error types and error feedback strategies in eTandem exchanges between L2 learners of English in China and L2 learners of Chinese in the UK. In our study, we partially adopted Bower and Kawaguchi's (2011) error categories in classifying the language errors as the two studies shared similarities in research context (theirs was a study between the learners in the East, i.e., Japan, and the West, i.e., Australia, while ours was between learners in China and the UK) in terms of the participants' backgrounds (both studies comprised tertiary level university students) and in the eTandem project organisation (both were coordinated and guided by their respective teachers). We combined the two error categories of pragmatic and idiomatic errors into one category as they often overlap. 
Furthermore, due to autocorrection on computers and smart phones as well as the convenience of online dictionaries, spelling errors no longer pose a major challenge to L2 English learners. We therefore focussed on the following three error types: lexical, grammatical and idiomatic.

In terms of error correction strategies, the analysis of our corrective feedback data was guided by previous studies (e.g., Lyster \& Ranta, 1997; Vinagre \& Lera, 2008; Vinagre \& Muñoz, 2011). Namely, we followed the explicit and implicit feedback categories with the aim of investigating if previously identified strategies under these two categories are adopted in relation to the error type, as well as exploring preferred error feedback by L2 learners of Chinese.

This study aimed to answer the following questions:

1) What types of language errors are made by Chinese L2 learners of English during eTandem exchanges, and what strategies of corrective feedback in relation to the error types are provided by competent L1 participants from the UK?

2) To what extent do Chinese participants respond to their eTandem partners' feedback in terms of attitudes, process and uptake?

It was hoped that the findings from this study would contribute to our understanding of corrective feedback practices by L2 learners in eTandem projects and to the design of more effective eTandem projects between eastern and western L2 learners.

\section{Methodology}

\subsection{Research context}

The present study was situated at two universities: one in China and one in the UK. The Chinese participants were from the Institute of Online Education of Beijing Foreign Studies University (BFSU), who were learning English for a bachelor's degree on a part-time basis through self-study of English language learning materials, weekly face-to-face meetings, synchronous and asynchronous online tutorials and multi-modal learner support services. The participants from the UK were from a leading distance learning university, The Open University (OU), and were at the beginner level of their Chinese language learning. They also studied on a part-time basis with a similar blended learning model as their Chinese counterparts.

The two groups of students (there were 24 participants in total at the start, but six did not complete the study) participated in the project on a voluntary basis. 
Based on findings from the previous research that it is crucial to provide guidance and ample support prior to and during online exchange projects (e.g., Kan et al., 2013; Lin et al., 2016), an email invitation was sent to targeted student groups in English about the project, which included a description of eTandem learning and the two key principles of reciprocity and autonomy, and what participants were expected to do if they volunteered to take part in the project. Once the participants decided to take part and submitted the consent form, they were presented with the following files: the pairing information with contact details of each pair, the timetable indicating the start date of each week with a suggested topic of the week, the weekly learning diary template to enhance reflection and record language and culture development (see Appendix II) and instructions for installing Skype and Callnote, an audio recording software add-on.

Each week, participants worked online in randomly matched pairs via synchronous Skype calls and asynchronous email exchanges. They were given assignments on a suggested topic as well as useful expressions in both languages (see Appendix I) one week before the scheduled exchange date. Participants in each pair were advised to spend a comparable amount of time using each language when they met on Skype, and they wrote about the same topic in both languages when they emailed. For their written exchanges, the guidelines highlighted that participants should not carry out literal translations of their writing from L1 into L2 on a particular topic, but that they could write slightly more in L1. The pairs were expected to give detailed corrective feedback on major mistakes concerning cultural misunderstanding, grammatical errors and/or repetitive misuse of the language in their written texts using the track changes feature.

\subsection{Participants}

Of the nine BFSU participants from China who completed the project, seven were female and two were male, with ages ranging from 27 to 50; they had studied English as a foreign language for at least eight years prior to this program. Most of them were in their second semester of study when they joined this project. All of them were in-service workers with full-time employment while learning English on a part-time basis. The nine OU participants from the UK consisted of five males and four females, with ages ranging from 26 to 76; they had completed one year of Chinese language learning prior to the project. Some of them had full-time employment and some were retired.

Two differences were observed between the two groups. The British participants were, on the whole, more senior in age than their Chinese partners, but their level of L2 language competence was much lower than their Chinese partners who 
had learnt English for many more years. These differences might have affected their collaboration, their respective language and cultural gains and their attitudes towards corrective feedback.

\subsection{The project's tasks}

The entire project lasted for six weeks. In light of Lee's (2006) finding that tasks with open-ended questions motivated more L2 use and negotiation, participants were provided with six topics that reflected real-life situations that they could easily relate to and freely discuss: getting to know each other, family and friends, food, the weekend, comparing things and travel.

Tasks were completed on a weekly basis. Six tasks completed by nine pairs were retained for analysis. None of the British or Chinese students had previous experience with offering language feedback via telecollaboration, and they were given a general piece of advice "not to over-correct. Choose the more serious mistakes and provide the correct or more appropriate words/expressions in a track change Word file" (see Appendix I) without detailed feedback strategies matched to error types.

\subsection{Data collection and analysis}

Table 1 presents our datasets and the data collected in relation to participants.

\subsubsection{Written work}

Due to the limited Chinese language competence of the OU participants, their written work was short in length with almost no idiomatic expressions. In addition, compared with the BFSU participants, the amount of written work sent to their L1 Chinese partners was significantly smaller than the other group. As a consequence, there was limited data regarding error types made by the OU participants. We excluded written work by L2 learners of Chinese from the data to focus on Chinese participants' work (i.e., L2 learners of English from BFSU in China). However, we included the 29 reply emails in English from the OU participants because they contained corrections using the track changes feature, allowing us to categorise error types in relation to the feedback strategies used. 


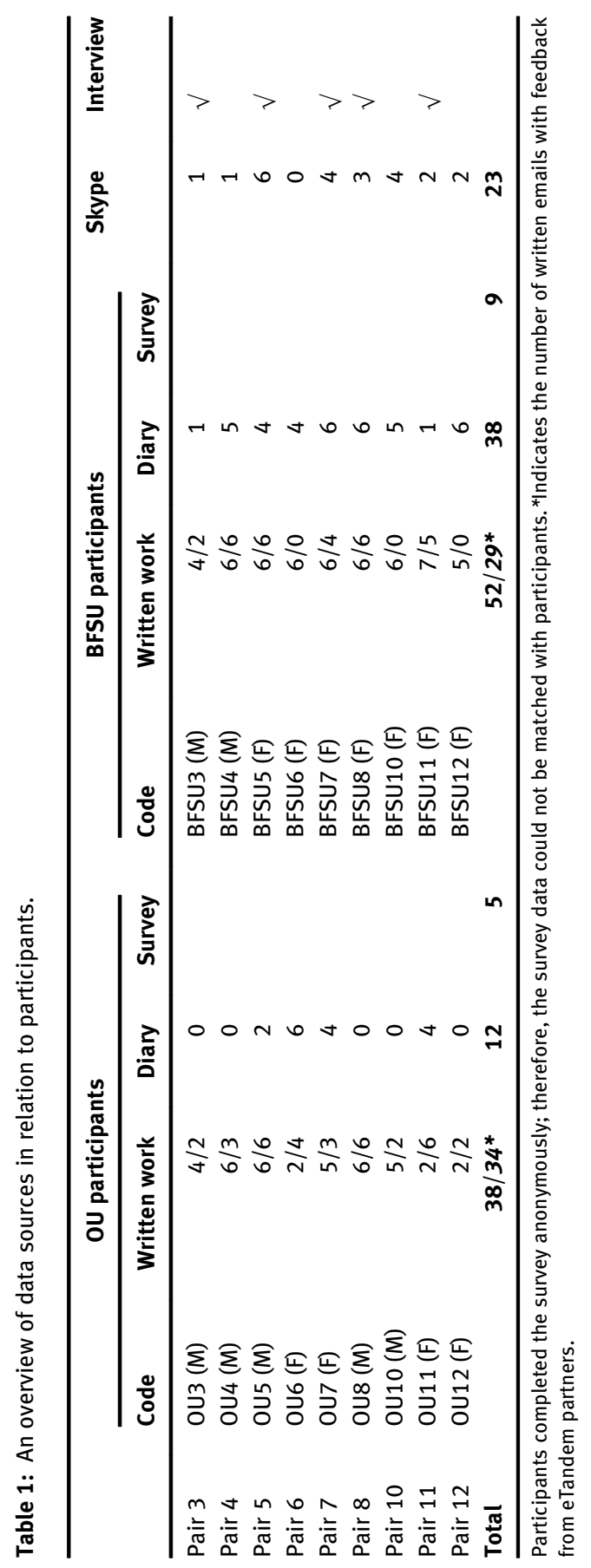




\subsubsection{Synchronous Skype recordings}

Twenty-three recorded Skype transcripts between eight pairs were analysed in this study (there was no Skype recording for Pair 6). Due to the lower L2 competency in Chinese, the length of time spent speaking English was much more than Chinese in every recording. What the OU participants gained out of the eTandem learning was cultural knowledge and enhancement of intercultural competence, which was evident from the learning diary data (but was not the focus of this research). We therefore concentrated on the errors that the Chinese participants made and the corrective feedback strategies that the OU participants employed to correct their partners during their Skype conversations.

\subsubsection{Learning diaries}

Twenty-three learning diaries were submitted by the BFSU participants, compared to only 12 by the OU participants. As the focus was on Chinese participants from BFSU and their attitudes towards corrective feedback, only the diaries from the BFSU participants were included in the data analysis.

\subsubsection{Post-project self-evaluation survey}

The survey was sent to all participating students following the end of the project. The questions were presented in English with a few difficult terminologies translated into Chinese to enhance understanding (see Appendix III). The survey consisted of both multiple choice and open comment questions. Fourteen responses were returned, of which only five were by OU participants. Data used in this paper was based on the nine responses from BFSU participants.

\subsubsection{Interviews}

To gain a better understanding of and further insight into eTandem learners' experiences, we interviewed five Chinese participants (BFSU 3, 5, 7, 8 and 11), three of whom participated in the semi-scheduled interviews (see Appendix IV for interview prompts) via online audio or video communication; the other two answered the interview questions in written form. These five interviewees were selected because of their availability and because they actively engaged in the project. The asynchronous email interviews comprised of nine open-ended questions in Chinese with the aim of further exploring the participants' attitudes towards corrective feedback. The three live interviews lasted for about $30 \mathrm{~min}$ each 
and were conducted in Chinese. They were recorded, transcribed and translated into English.

Due to the small sample size and the nature of our data, a qualitative approach was used in the analysis of the learning diaries, open-ended comments in the survey and interview transcripts/answers. They were analysed manually and coded into broad themes using a thematic analysis method (Braun \& Clarke, 2006). Descriptive statistics from the survey and email exchanges were triangulated with the qualitative data whenever appropriate.

Error analysis was guided by Bower and Kawaguchi's (2011) approach to manually tagging errors into the following categories: grammatical errors, lexical errors (i.e., vocabulary) and errors of idiomatic expressions. Informed by Lyster and Ranta (1997), Vinagre and Lera (2008) and Vinagre and Muñoz (2011), we examined three corrective feedback strategies (explicit correction, metalinguistic explanation and clarification requests) in the corrected emails from competent L1 partners from the UK as well as the recorded Skype transcripts. The category of "metalinguistic explanation" includes explanation about grammar, style and appropriateness.

\subsection{Findings and discussion}

Our main findings are reported in relation to the two research questions.

Table 2 sums up the two research questions and the corresponding data sources.

Table 2: Research questions and data sources.

\begin{tabular}{ll}
\hline Research questions & Data sources \\
\hline $\begin{array}{l}\text { 1. What types of language errors are made by Chinese L2 } \\
\text { learners of English during eTandem exchanges, and }\end{array}$ & Emails and Skype recordings \\
what strategies of corrective feedback in relation to the & \\
error types are provided by competent L1 participants & \\
from the UK? & Emails, the post-project survey, \\
$\begin{array}{l}\text { 2. To what extent do Chinese participants respond } \\
\text { to eTandem partners' feedback in terms of attitudes, } \\
\text { process and uptake? }\end{array}$ & learner diaries, interviews \\
\hline
\end{tabular}

Question 1. What types of errors are made by Chinese L2 learners of English during eTandem exchanges, and what strategies of corrective feedback in relation to the error types are provided by competent $\mathrm{L} 1$ participants from the UK? 


\subsubsection{Error types}

There were 366 errors identified (see Table 3), with grammatical errors (58.2\%) occurring more than twice as frequently as idiomatic (21.6\%) and lexical (20.2\%) errors. An interesting observation is that lexical errors and idiomatic errors numbered about the same (about 20\%), which might be caused by that the partners were involved in discussing real-life topics and more idioms might be used.

Table 3: Linguistic categories of errors.

\begin{tabular}{llr}
\hline & Types of Errors & Occurrences \\
\hline 1 & Grammatical & $213(58.2 \%)$ \\
2 & Idiomatic expressions & $79(21.6 \%)$ \\
3 & Lexical/Vocabulary & $74(20.2 \%)$ \\
& Total & $366(100.0 \%)$ \\
\hline
\end{tabular}

Compared to other studies (e.g., Bower \& Kawaguchi, 2011; Kabata \& Edasawa, 2011), the types of learner errors in this study were more unequally distributed. This may have been caused by the major differences in grammatical structures between Chinese and English, or by the lower-intermediate proficiency level of the Chinese L2 learners' English, which made learners more likely to make grammatical mistakes.

\subsubsection{Feedback strategies}

In terms of corrective feedback strategies, explicit correction accounted for $84.2 \%$ of the correction strategies used, as shown in Table 4 below, which might have been due to the fact that eTandem participants were informed prior to the project not to "over-correct" but to point out "more serious mistakes and provide the correct or more appropriate words/expressions" using the track changes feature (cf. Methodology); however, they were not provided with sufficient guidance on other error correction strategies. Explicit corrections include replacing or reformulating one word/phrase with another. The category of metalinguistic explanation includes explanations that use metalinguistic terms such as "verb" and "past tense" as well as explanations about the style, colloquial expressions, etc. Both explicit correction and metalinguistic explanation fall into the category of explicit feedback, while clarification requests are implicit feedback. 
Table 4: Categories of corrective feedback strategies.

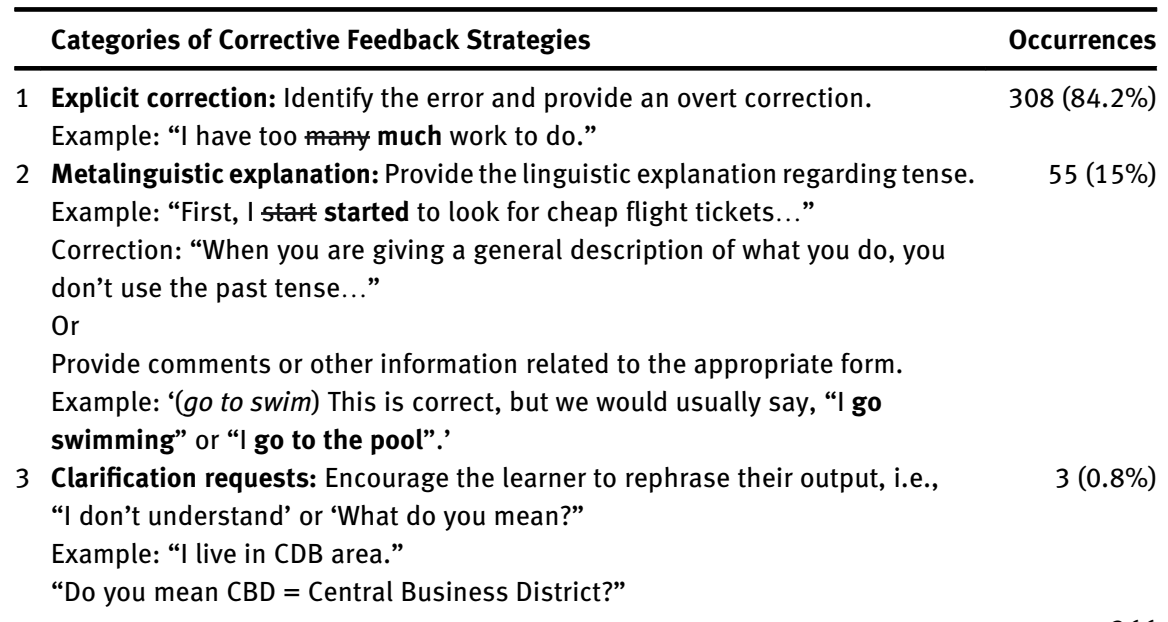

Table 5 offers an overview on the types of errors and their corresponding error correction strategies. The largest number of grammatical errors $(n=196)$ was corrected explicitly, which reinforces earlier research studies by Bower and Kawaguchi (2011), in whose study reformulation was the most commonly adopted strategy to correct grammatical errors. The explanation strategy was used most $(n=21)$ in correcting idiomatic expression errors, which is not surprising, as the meaning of idioms in the target language is often not self-explanatory.

Table 5: Frequency and percentage of errors and corrective feedback strategies (emails).

\begin{tabular}{lrrrr}
\hline Feedback strategies & \multicolumn{4}{c}{ Linguistic errors } \\
\cline { 2 - 5 } & Grammar & Idiomatic expressions & Vocabulary & Total \\
\hline Explicit correction & 196 & 58 & 54 & $\mathbf{3 0 8 ( 8 4 . 2 \% )}$ \\
Metalinguistic explanation & 17 & 21 & 17 & $\mathbf{5 5 ( 1 5 \% )}$ \\
Clarification requests & 0 & 0 & 3 & $\mathbf{3 ( 0 . 8 \% )}$ \\
Total & $\mathbf{2 1 3 ( 5 8 . 2 \% )}$ & $\mathbf{7 9 ( 2 1 . 6 \% )}$ & $\mathbf{7 4}(\mathbf{2 0 . 2} \%)$ & $\mathbf{3 6 6 ( 1 0 0 . 0 \% )}$ \\
\hline
\end{tabular}


Sample email entry (grammatical errors) (Note: corrections from L1 speakers are in italics.)

(1) [Explicit correction] My home located (is located) in...

(2) [Metalinguistic explanation] I often make fried dishes and chicken soup for dinner, but that will take (takes) a long time to cook. ([Comment] "takes" because it is an action that happens usually. "Will take" is an action that happens in the future.)

Sample email entry (lexical errors/errors related to vocabulary)

(1) [Explicit correction] We now live in the outskirt (outskirts) of Beijing with our parents, ...

(2) [Metalinguistic explanation] ... and we had eaten a lots of seafood. ([Comment] "we had lots of" or "we ate lots of"; "a lot of" or "lots of"-either one is OK, but you can't mix them up.)

(3) [Clarification requests] Every day we enjoyed the sunshine and see beautiful scenery ([Comment] "saw beautiful scenery" or "beautiful sea scenery"-I'm not sure which you meant).

Sample email entry (errors related to idiomatic expression)

(1) [Explicit correction] In my hometown, there are many snow (it snows a lot) in winter.

(2) [Metalinguistic explanation] I deeply appreciate their help. (I appreciate their help very much.) ([Comment] "deeply appreciate"-it's not wrong but sounds too formal in this situation.)

As revealed in the open-ended comment questions in the survey, more than half of the Chinese participants from BFSU preferred a written form of correction in the chat box rather than have mistakes verbally pointed out during their Skype conversations. It could be that both partners were concerned that error correction might interrupt the conversation flow, which was one of the findings in Bower and Kawaguchi's study (2011). Interestingly, the corrective feedback during the Skype conversations was mostly provided via the strategies of explanation, clarification requests or repetition.

As shown in the Skype transcription below, the OU participant tried to clarify their partner's real meaning by asking “What do you mean by 'formal'?". More explanation followed for this inappropriate wording and then the proper expression was also elicited.

Sample Skype Recording, Extract 1

A (BFSU 5): OK. So, when I do the interview, I can say my children have grown up, so I want to find one formal and full-time job. 
B (OU 5): Yeah. What do you mean by "formal"?

A: Oh, formal, which job I can develop my career.

$B$ : All right, $O K$.

A: So, I must change, yeah.

B: Er, formal, "full-time" is OK; "formal" sounds a bit odd.

A: Oh.

B: OK, I want to find..., yeah, I think you need to explain it a little bit more. I need

to find, I want to find a full-time job more suited to my career.

The following extract displays another strategy employed by the OU participant, i.e., repetition. When asked which one is correct, "family in-laws or my in-laws", the OU participant repeated the latter one, "my in-laws" to help correct his partner. Sample Skype Recording, Extract 2

A (OU 5): Yeah, now is in English, you can say, uh, you can talk about your inlaws, which means all, all [the] family of your wife or of your husband.

$B$ (BFSU 5): Ah, so, so I can say my relatives in-laws.

A: Well, relatives, I think, would include your in-laws.

B: Uh, family in-laws, right?

A: No, just, um...

$B$ : Family in-laws or my in-laws, ah, my in-laws.

A: My, my in-laws. You don't, you don't need to say family.

B: Okay, okay, [I] understand now. Yeah.

In email exchanges, the first two strategies were used more than clarification requests, while in Skype conversations, there were far more occurrences of clarification requests (sometimes with metalinguistic explanation). Below we will reveal and discuss our findings regarding how Chinese participants responded to their partners' feedback.

\section{Question 2. To what extent do Chinese participants respond to their eTan- dem partners' feedback in terms of attitudes, process and uptake?}

To answer this question, we first needed to understand participants' overall attitude towards the eTandem project. Eight out of nine Chinese participants responded positively to the benefits of eTandem learning, both from general and personal aspects in the two open questions-Q12 (Generally speaking, what do you think are the benefits of eTandem learning?) and Q18 (What were the benefits of the exchange for you, personally?)-in the survey (see Appendix III). The four most frequently mentioned benefits were improved communication skills, friendship, self-confidence and cultural awareness. When asked in the survey to choose from a list of linguistic and cultural aspects that the project helped to improve (Q14), the 
following were the most popular: interactive speaking (88.89\%), understanding of spoken language (77.78\%), cultural understanding $(77.78 \%)$ and range of vocabulary (55.56\%).

The overall favourable experience of this eTandem learning project seems to have had a positive impact on participants' attitudes towards corrective feedback, as indicated below:

"This was a great project. Generally speaking, Chinese students are very shy and always afraid of making mistakes in the public. It is a good chance for English learning that the English partners helped us improve through correcting our errors in communication." [BFSU 8, interview]

"I think this project organised by the two universities provided a very good and secure online environment where I, an English learner, can interact with a competent English speaker who wants to learn Chinese. We felt very safe in our communication. More importantly, my eTandem partner was very conscientious in learning and teaching, and inspired by our mutual dedication, we had completed the six assignments successfully.”[BFSU 5, interview]

The other three interviewees all expressed the same sentiment, revealing that the big advantage of eTandem learning was the opportunity for individual and personalised learning. Most importantly, learners felt they were in a safe space (Woodin, 2020), so they did not need to worry about losing face in public when being corrected; this confirms the findings in Woodin's (2020) and KukulskaHulme et al.'s (2021) studies. Next, we will reveal and discuss the Chinese participants' responses to the corrective feedback in this safe space.

\subsubsection{High uptake on corrections of grammatical errors}

Table 6 shows how Chinese participants reacted to their partners' feedback: 54 $(n=54)$ out of 366 error corrections were overtly attended to in later written work, which was more than twice the number of error corrections not addressed $(n=23)$. However, we must be mindful that for the majority of error corrections $(n=289$, $79 \%$ ), the data did not capture whether the participants had become aware of these errors and were able to correct them. The main reasons for the largest number of

Table 6: Uptake percentage of feedback in relation to error category.

\begin{tabular}{lrrr}
\hline Linguistic error category & Uptake & No uptake & No indicator \\
\hline Grammar & $37(10.1 \%)$ & $18(4.9 \%)$ & $158(43.2 \%)$ \\
Idiomatic expression & $11(3.0 \%)$ & $2(0.5 \%)$ & $66(18.0 \%)$ \\
Vocabulary & $6(1.6 \%)$ & $3(0.8 \%)$ & $65(17.8 \%)$ \\
Total & $54(14.8 \%)$ & $23(6.3 \%)$ & $\mathbf{2 8 9}(79.0 \%)$ \\
\hline
\end{tabular}


"No indicator" are twofold. Firstly, project tasks varied from week to week-as did the topic themes-which affected language and grammatical points used. Secondly, in Week 6, i.e., the final week, though 61 errors were corrected, their uptakes could not be traced as the participants were no longer in communication for this project.

Among the different error types, grammatical error correction had the highest uptake in later emails $(n=37)$, followed by idiomatic expression $(n=11)$. Below are a few examples:

(Note: The corrections from L1 speakers are in italics.)

Samples of uptake [grammar]

[BFSU 5-Week 1 email] ...so I have few (little) time to speak English.

[BFSU 5-Week 4 email] ...we have little time to talk.

[Learning diary]

BFSU Participant 4 revealed in his diary: "I noticed many errors pointed out by my partner in the use of prepositions, so I paid attention in later written work." (In his following five email exchanges, there were no errors in relation to prepositions.)

[Skype conversation]

BFSU Participant 8 learned how to use the demonstrative pronouns "this" and "that" to refer to the objects that had been mentioned during the conversation with her partner, so she put that into practice:

$A$ (OU 8): Oh, yes, you showed me that picture of your very large family.

$B$ (BFSU 8): Yeah, yeah, that is my father's side.

\section{Sample of uptake [idiomatic]}

[BFSU 11-Week 3 email] I come from Hubei Province in China, so I like hot (spicy) food very much.

[BFSU 11-Week 6 email] My favourite food is Guilin rice noodles. If you like spicy food, you can add some pepper.

Sample of uptake [vocabulary]

[Learning diary]

BFSU Participant 6 related in her diary: 'They [competent English speakers] always use “would like”, not “want”; it is polite.' (In the following email for week 3, this participant applied this into her writing: "I would like to hear about your food.")

Some researchers, such as Ellis, Basturkmen, and Loewen (2001), categorised corrective feedback into successful (the correct form is reused) and unsuccessful (the feedback is acknowledged but it is not reused by the learner). It is encouraging that some of the participants learned from their partners' feedback and reused the suggested words/phrases in some of their later exchanges. In that sense, the 
feedback was successful, which might have also contributed to their English language competence as reported by the Chinese participants in the survey.

\subsubsection{Positive relation between explicit correction strategy and feedback uptake}

Regarding how the different types of feedback strategies affected feedback uptake (Table 7), our data has shown that the explicit correction strategy led to the largest number of uptakes $(n=47,12.8 \%)$, twice as much as "No Uptake" ( $n=23,6.3 \%)$. This finding echoes earlier studies, such as from Akiyama (2017), whose participants preferred recasts, and the number of uptakes was positively related to their favoured ways of giving and receiving feedback. This may be linked to the fact that the more grammar-focused English language teaching pedagogy in China (e.g., Deng \& Lin, 2016) makes students pay more attention to grammatical errors.

However, such causal relation needs to be treated with caution due to the following three reasons: 1) the correction of grammatical errors such as the use of wrong tense or wrong relative clause is highly applicable to other situations, regardless of topic areas; 2) participants could have learnt them elsewhere; and 3) many idiomatic expressions are only appropriate when discussing certain topic areas, so participants had no opportunity to uptake the corrections.

Table 7: Counts of different corrective feedback strategies leading to uptake.

\begin{tabular}{lrrr}
\hline Categories of feedback strategies & Uptake & No uptake & No indicator \\
\hline Explicit correction & $47(12.8 \%)$ & $23(6.3 \%)$ & $238(65.0 \%)$ \\
Metalinguistic explanation & $7(1.9 \%)$ & 0 & $48(13.1 \%)$ \\
Clarification requests & 0 & 0 & $3(0.8 \%)$ \\
Total & $54(14.8 \%)$ & $23(6.3 \%)$ & $\mathbf{2 8 9}(79.0 \%)$ \\
\hline
\end{tabular}

\subsubsection{Consciously attending to corrective feedback}

A close study of email communication revealed that the Chinese participants varied in the number of error uptakes (see Table 8). The interview data strongly indicates that those who took conscious steps in implementing correction feedback either demonstrated high uptake of corrective feedback (e.g., BFSU 8) or succeeded in avoiding further errors, which resulted in fewer errors and, hence, fewer corrections and uptakes (e.g., BFSU 7): 
Table 8: Uptake percentage of different participants.

\begin{tabular}{lrrrr}
\hline Participants & Uptake & No uptake & No indicator & Total \\
\hline BFSU 3 & $3(18.8 \%)$ & $0(0.0 \%)$ & $13(81.3 \%)$ & $\mathbf{1 6}$ \\
BFSU 4 & $3(16.7 \%)$ & $0(0.0 \%)$ & $15(83.3 \%)$ & $\mathbf{1 8}$ \\
BFSU 5 & $20(11.8 \%)$ & $19(11.2 \%)$ & $131(77.1 \%)$ & $\mathbf{1 7 0}$ \\
BFSU 7 & $1(4.5 \%)$ & $0(0.0 \%)$ & $21(95.5 \%)$ & $\mathbf{2 2}$ \\
BFSU 8 & $20(19.0 \%)$ & $2(1.9 \%)$ & $83(79.0 \%)$ & $\mathbf{1 0 5}$ \\
BFSU 11 & $7(20.0 \%)$ & $2(5.7 \%)$ & $26(74.3 \%)$ & $\mathbf{3 5}$ \\
Total & 54 & $\mathbf{2 3}$ & $\mathbf{2 8 9}$ & $\mathbf{3 6 6}$ \\
\hline
\end{tabular}

I wrote new emails with the corrected forms consciously. I often looked through the previous emails if I realised I had made that error before, but I did not check the previous communication record every time. [BFSU 8, interview]

I checked grammatical errors very carefully, such as the usage of "where" and "which", which reinforced my memory of the grammar rules. [BFSU 7, interview]

\subsubsection{Corrective feedback on idiomatic errors most valued}

Although explicit correction on grammatical errors had the highest in uptake (see Tables 5 and 6), our interview data indicated that what L2 participants valued most (and also remembered most) was the correction on idiomatic expressions:

I remembered the errors about idiomatic expressions more clearly. For example, I often use "could" which was corrected to "be able to" by my partner. After this correction occurred many times, I could remember it. [BFSU 5, interview]

I remembered the errors about some authentic expressions more clearly like "spicy food". My grammar is relatively poor, and I was seldom exposed to [a] real language environment. "Spicy food" is an idiomatic expression, which is different from Chinese understanding, so that is very impressive. [BFSU 11, interview]

This is supported by data from the survey and learning diaries when asked about the expressions/words learned and remembered. The majority of them were colloquial and idiomatic expressions:

dogsbody, binge-watch, copycat, it's sick or wicked [quotes from survey]

I had a laugh, snap back, grit one's teeth, get a lie-in [quotes from learning diaries]

Learners value these idiomatic expressions because they are vivid, witty, humorous and closely linked with real life scenarios, and also because they can rarely be learnt from textbooks and foreign language classrooms. As the Chinese students in this study have limited interactions with competent L1 English speakers, they have few opportunities to hear those idiomatic expressions being 
used in authentic communication such as provided by the eTandem project, which makes it even more memorable.

\subsubsection{Importance of real-life topics for communication}

Participants also revealed why they paid more attention to the corrective feedback from their English eTandem partners in comparison to their Chinese teachers:

There is a big difference. Chinese teachers tend to focus on correcting vocabulary and grammar errors while my eTandem partner tends to pay more attention to the authentic and idiomatic use of the language to see whether the language is explicit, idiomatic and to the point. [BFSU 7, interview]

A huge difference exists. For example, our English teacher assigned us homework from the book. Content and language are not closely related to our daily life, and their feedback tends to focus on grammar. ... With our eTandem learner, what we are discussing is about things happening in our daily life, the language used is more authentic and useful, and we can remember their feedback on our errors much better and can make effective use of it. [BFSU 11, interview]

The above quotes tell us that what really matters to language learners is that topics for communication, whether written or spoken, should be relevant to their lives. When the structured tasks are topics learners can relate to, they are more likely to stimulate discussion and negotiation of meaning than free conversations (Bower \& Kawaguchi, 2011). For example, the topic of making comparisons in this study encouraged participants to do more in-depth research, raised awareness of the differences of life between China and the UK and yielded the largest amount of written output in emails. It is evident from the data that highly motivated participants were more likely to take up the corrective feedback. The data also indicates that when communication topics are about real-life scenarios, corrections from competent L1 partners contained not only grammatical and vocabulary corrections but also interesting idiomatic expressions which learners value.

\subsubsection{Valuing more explanation with examples in the feedback}

Regarding their preferences to corrective feedback strategies, all five interviewees mentioned that more explanations from their partners were of great importance for better understanding. Besides, one of them would like her partner to give her more examples of usage:

I prefer explanatory feedback. First, let me know where I have made the mistake; then, why I have made the mistake; third, the correct version. [BFSU 11, interview] 
I hope that my partner not only can point out my errors but also explain the reason and give me more examples or strategies to avoid making the same errors. [BFSU 5, interview]

It is interesting that their own preference for the type of received feedback seemed to have influenced the strategy they themselves used when providing feedback to their partners:

Yes, I like being corrected and also like helping my partner with his Chinese. I would tell him what...the idiomatic Chinese expression [is], what is the reason, and then [give] him more examples. [BFSU 5, interview]

The data also revealed the shortcomings in the project's design: lack of clear guidance on corrective feedback strategies:

It would be great if we were trained on how to correct our partners' errors before our communication. Our corrections would be easier for our partner to understand, and the result would be better. [BFSU 8, interview]

It seems that by reflecting during the interview about receiving and giving feedback, the interviewees were not only able to identify their learning needs but also provided us with valuable suggestions.

\section{Conclusions}

This study demonstrated that most language learners are willing to communicate and feel that they benefit from communicating through asynchronous email exchanges and synchronous Skype conversations with competent L1 speakers in virtual exchange programmes like this one. Such enthusiastic learner participation provided this study with rich data so that the two research questions could be addressed satisfactorily. In summary, the study identified three error types made by Chinese learners of English (grammatical, lexical and idiomatic errors) and three main strategies used by competent L1 partners in correcting those errors (explicit correction, metalinguistic explanation and clarification requests).

As most errors made were grammatical errors due to the participants' level of English competency, the amount of grammatical error correction, therefore, was high. The most-used strategy to correct grammatical errors was explicit correction, which was an easier and less time-consuming strategy to correct the mistakes, especially in written form. It is therefore natural that the uptake of grammatical corrections was the highest in this study. On the surface, it seems to suggest that explicit corrective feedback is more effective than implicit corrective feedback (Ellis, 2006; Varnosfadrani \& Basturkmen, 2009), but such a suggestion needs to 
be interpreted with discretion as many other factors were at play, such as the high number of grammatical errors, the grammar-focused pedagogy in China and the larger amount of data from written email exchanges than from Skype recordings. It is interesting that metalinguistic explanation and clarification requests were the most used corrective feedback strategies during the synchronous Skype conversations. It could be that during conversations, it was easier to explain and to clarify. This suggests that the preferred or often-used feedback strategies depend on the mode of communication. As stated earlier, the project's having different topics made the tracking of corrective feedback on categories other than grammar difficult to undertake.

Below are three important findings from this study derived from the investigation of how L2 Chinese learners of English responded to the corrective feedback in terms of their attitudes, the process, their preferred corrective feedback and reasons behind the preferences.

Firstly, the very nature of the eTandem learning programme, which is arranged by two participating universities and which advocates that competent L1 partners should play the role of teacher in offering corrections, offers a secure space where two partners trust each other and point out each other's errors in a personalised way. This offers the advantage of personalised learning, whereby feedback becomes part of the lesson (Kukulska-Hulme et al., 2021), which is extremely helpful for Chinese participants who are usually withdrawn and reluctant to speak English in public for fear of making mistakes and losing face.

Secondly, learners are more responsive to corrective feedback when the communication encounters are authentic, like communicating with an eTandem partner, and the topics of communication are relevant to real life. This is because during these real-life communications, one is more likely to come across an interesting idiomatic expression that is not mentioned in textbooks, but is memorable and applicable in later conversations. Also, many participants value friendship, so they have increased motivation to make themselves better understood as well as the desire to take on board the corrective feedback from their partners. As a result, all the Chinese participants felt some improvement in their English language proficiency.

Finally, although our research participants responded well to explicit corrections to their grammatical mistakes, many of them would have liked to have feedback with explanations and examples since those would help them to become independent learners. This suggests to us that eTandem participants may benefit more from eTandem learning in terms of linguistic improvement when participating partners are well-trained in error correction feedback.

There are several limitations of this study: 1) the sample size was too small (only nine pairs of participants) for the findings to be conclusive; 2) of those nine 
pairs, three OU participants did not provide corrective feedback and the reasons were not investigated; 3) only active Chinese participants were interviewed, so we were not able to report on how less active participants felt about corrective feedback strategies.

Nevertheless, the study does provide us with some insight on how future eTandem projects can improve in terms of error feedback. The weekly activity guidelines were too general and simplistic, which resulted in an overwhelming use of explicit corrections. In future telecollaborative projects on language development, it will be important to provide participants with guidelines on 1) common types of error correction strategies and how to apply them with concrete examples; 2) what steps to take after receiving corrective feedback and how to treat feedback as part of learning; and 3) the importance of discovering an eTandem partner's learning style and corrective feedback preference.

The above three aspects can be embedded into the weekly activity guidelines and the learning diary to encourage reflection and acceptance of corrective feedback. The guidance on the recommended types of error corrections will depend on the language proficiency level. For lower and intermediate level L2 Chinese learners of English, our study showed that the following three types are effective: explicit correction, metalinguistic explanation and asking for clarification. But would too much training take away the element of authentic communication? How can we achieve the balance between effectively briefing the eTandem participants on the above areas and an authentic communicative environment? This question is worth researching for future studies.

Research funding: This study was funded by the Project of Discipline Innovation and Advancement (PODIA)-Foreign Language Education Studies (Ref: 2020SYLZDXM011) and the Project of Artificial Intelligence and Human Languages Lab (Ref: 2020SYLZDXM040) at Beijing Foreign Studies University.

\section{Appendix I: Weekly activity guidelines}

\section{Email and Skype worksheet (topic: travel)}

\section{What to do?}

Have you sent your eTandem partner corrections to his/her last email? If not, do this before starting the next email exchange. Please remember not to over-correct. Choose the more serious mistakes and provide the correct or more appropriate words/expressions in a track change Word file. 
Then write an email to your eTandem partner in both Chinese and English as usual: do not directly translate the text but make sure that the language you use in your native language is at the right level for your partner to understand (reminder: the OU students' level of Chinese is intermediate).

After you have arranged a mutually convenient time, log in to Skype and start your dialogue with your partner. Remember to record the conversation by clicking the Record button at the bottom of your screen.

\section{Guidelines}

In this last eTandem exchange of the project you will be talking or writing about your holidays and travels, describing places you have visited and things you like about a particular place, and you will be talking about plans for your next journey. You can also make arrangement with your partner to visit each other. But please make sure that you distinguish between hypothetical plans for the sake of language practice and actual arrangements for visits and travel.

\section{Useful phrases}

Here are some words and phrases that can help you; use an online dictionary if you like to check the following terms:

\begin{tabular}{ll}
\hline English & Chinese \\
\hline I love travelling, but visa is an issue. & 我喜欢旅游, 可是签证是一个问 \\
& 题。 \\
I worry about flying. & 我担心坐飞机。 \\
I have been to China/US once/twice. & 我去过一次/两次中国/美国。 \\
Talking about Beijing/London, there are two aspects I like & 说起北京/伦敦, 我喜欢两个方 \\
about the place.... But I don't like... & 面...可是我不喜欢... \\
(Beijing/London) is beautiful, however/but... & (北京/伦敦) 美是美, 可是... \\
Do you like package tours or travelling independently? & 你喜欢跟旅游团一起度假还是自 \\
& 己度假? \\
Where did you go for your last holiday? & 你上一次度假去什么地方/哪儿 \\
& 了? \\
Where do you plan to go for your next holiday? & 你下次打算去什么地方度假? \\
What do you like doing when you are on holiday? & 你度假的时候喜欢做什么? \\
Have you been to...? & 你去过... 吗? \\
Would you like to go on holiday with me? & 你想和我一起度假吗? \\
When is the best time for you? & 对你来说, 什么时候最好? \\
\hline
\end{tabular}

For useful phrases for a Skype conversation, you can also refer to the above table. 


\section{Appendix II: Weekly learning diary}

Please take a short time reflecting on the following aspects of your exchange and write down your reflections in the appropriate space (the field will expand so you can write as much as you like):

Did you Skype this week? If so, for how long?

What are the main things you learnt this week?

What challenges/issues did you encounter this week?

What part of this week's exchange did you enjoy most?

What new words and expressions have you learnt from your partner?

Have you tried to use them in your communication?

Have you learnt anything else (e.g. about aspects of your partner's

culture) this week?

Anything else you want to note down about this week?

\section{Appendix III: The Chinese-English eTandem survey}

1. Study. Please tick the phrase that corresponds to your current status.

$\square \quad$ Full-time student

$\square \quad$ Part-time student

$\square$ Having a break from formal study

2. Education. Please tick the phrase which corresponds to your highest educational achievement prior to studying languages with us.

$\square \quad$ No qualifications

$\square$ GCSE

$\square$ A-level

$\square \quad \mathrm{BA} / \mathrm{BSc}$

$\square \mathrm{MA} / \mathrm{MSc}$

$\square \quad$ Other

3. What were your expectations before you started the exchange? What did you hope to gain from taking part in the e-Tandem project? Choose any answers that apply.

$\square$ understand the spoken foreign language better

$\square$ speak the foreign language more fluently

$\square$ more accurate grammar 
$\square$ more accurate pronunciation

$\square$ a wider range of vocabulary

$\square$ feel more confident using the foreign language

$\square$ be able to interact with foreign language speakers

$\square$ make friends with someone from another culture

4. Have your expectations of the e-Tandem project been met?

$\square \quad$ Exceeded my expectation

$\square \quad$ Met my expectation

$\square \quad$ Did not meet my expectation

5. What is your evaluation of the e-Tandem project?

$\square \quad$ Extremely useful

$\square \quad$ Very useful

$\square \quad$ Quite useful

$\square \quad$ Not sure

$\square \quad$ Not sure at all

6. List the topics you discussed, in order of preference.

7. Describe one Skype session or email exchange that worked really well for you and explain why.

8. Describe a session or exchange that did not work well and explain why it did not work.

9. How did you correct your e-Tandem partner during Skype sessions?

$\square \quad$ Written correction using text chat

$\square$ Spoken correction in mid-conversation

$\square \quad$ Other

10. How did your e-Tandem partner correct you during Skype sessions?

$\square \quad$ Written correction in text chat.

$\square$ Spoken correction in mid-conversation

$\square \quad$ Other

11. What type of correction worked best for you?

Elicit correction of your error

$\square \quad$ Explanation of grammar rules

$\square \quad$ Elicitation of the correct form

$\square$ Repetition of your error(as a prompt) 
$\square \quad$ A correct reformulation

$\square$ A request for clarification

12. Generally speaking, what do you think are the benefits of e-Tandem learning?

13. Did the project improve your confidence in speaking and writing in Chinese/English? Why or why not? Please select.

$\square \quad$ Yes

$\square \quad$ No

$\square \quad$ Not sure

$\square \quad$ Other

14. Which aspect(s) of your Chinese/English has the project helped you to improve? Tick any that apply.

$\square \quad$ Interactive speaking

$\square$ Understanding the spoken language

$\square \quad$ Accuracy and range of writing

$\square \quad$ Reading comprehension

$\square$ Grammatical accuracy

$\square$ Accuracy of pronunciation

$\square \quad$ Range of vocabulary

$\square \quad$ Cultural understanding

15. List three favourite expressions or phrases you learnt from your partner.

16. List three new things you learnt from your partner about your partner's country and its culture.

17. Did you notice any change of attitude in yourself or your partner, as a result of your exchange?

18. What were the benefits of the exchange for you personally?

19. What was/were the main difference(s) you noticed between yourself and your e-Tandem partner?

$\square \quad$ Language competence

$\square$ Ability to communicate across cultures

$\square$ Personal interests/hobbies/pastimes 
$\square$ Understanding of counterpart's culture

$\square$ Commitment to the project

$\square \quad$ Other

20. Did any of these differences impact on your learning of the language, on learning about your partner's culture, or on the learning experience itself?

21. What were the main difficulties or frustrations you encountered in e-Tandem learning?

22. What advice would you give to future e-Tandem learners?

23. What (for you) is the ideal length of an e-Tandem exchange?

$\square$ Shorter than five weeks

$\square \quad$ Five to ten weeks

$\square \quad$ Longer than ten weeks

24. Did you communicate with your e-Tandem partner outside the suggested weekly activities? If so, what form did this take?

25. Do you have any plans to continue working with your e-Tandem partner after the exchange?

$\square \quad$ Yes

$\square \quad$ No

$\square \quad$ Maybe

26. Do you have any comments on the e-Tandem project, or on learning Chinese or English with a native speaker?

27. Would you be happy to be interviewed online, to discuss your e-Tandem learning experiences further? If yes, please leave your email address.

\section{Appendix IV: Interview prompts}

1. How did you treat the emails with corrective feedback after you received them from your partner? 
2. Which kind of modified errors impressed you most? (i.e., vocabulary, grammar, or idiomatic expression)

3. Which kind of corrective feedback strategies helped you most? (i.e., explicit correction, metalinguistic explanation, or clarification requests)

4. For the errors you corrected in following emails, did you apply them consciously or unconsciously? Did you look through the previous emails with the same errors?

5. Are there any differences in terms of the corrective feedback that your English partner and your Chinese teacher(s) give?

6. How did you feel about the corrective feedback from you partner?

7. Would you like to provide corrective feedback for your partner?

8. How do you understand autonomy principle and reciprocity principle of eTandem learning?

9. What was the most rewarding thing for you about this project? Which aspects of the project could be improved in your opinion?

\section{References}

Akiyama, Y. (2017). Learner beliefs and corrective feedback in telecollaboration: A longitudinal investigation. System, 64, 58-73.

Barbosa, M. W., \& Ferreira-Lopes, L. (2021). Emerging trends in telecollaboration and virtual exchange: A bibliometric study. Educational Review. Retrieved from https://www. tandfonline.com/doi/full/10.1080/00131911.2021.1907314.

Bartram, M., \& Walton, R. (1991). Correction: A positive approach to language mistakes. Hove: Language Teaching Publications.

Bower, J., \& Kawaguchi, S. (2011). Negotiation of meaning and corrective feedback in Japanese/ English eTandem. Language, Learning and Technology, 15(1), 41-71. Retrieved from http:// llt.msu.edu/issues/february2011/bowerkawaguchi.pdf.

Braun, V., \& Clarke, V. (2006). Using thematic analysis in psychology. Qualitative Research in Psychology, 3(2), 77-101. Retrieved from http://eprints.uwe.ac.uk/11735.

British Council. (2018). Language trends 2018: Language teaching in primary and secondary schools in England. Retrieved from https://www.britishcouncil.org/sites/default/files/ language_trends_2018_report.pdf.

Deng, F., \& Lin, Y. (2016). A comparative study on beliefs of grammar teaching between high school English teachers and students in China. English Language Teaching, 9(8), 1-10. Retrieved from https://files.eric.ed.gov/fulltext/EJ1103455.pdf.

Dooly, M., \& O’Dowd, R. (Eds.) (2018). In this together: teachers' experiences with transnational, telecollaborative language learning projects. Switzerland: Peter Lang Bern.

Duff, P., Anderson, T., Ilnyckyj, R., VanGaya, E., Wang, R., \& Yates, E. (2013). Learning Chinese: Linguistic, sociocultural, and narrative perspectives. Berlin: De Gruyter.

Ellis, R. (2006). Modelling learning difficulty and second language proficiency: The differential contributions of implicit and explicit knowledge. Applied Linguistics, 27(3), 431-463. 
Ellis, R. (2007). Corrective feedback in theory, research and practice. Keynote speech presented at the fifth international symposium of ELT in China. Beijing, China.

Ellis, R., Basturkmen, H., \& Loewen, S. (2001). Learner uptake in communicative ESL lessons. Language Learning, 51, 281-318.

García, O. (2009). Bilingual education in the 21stcentury: A global perspective. Oxford: Wiley/ Blackwell.

Giguère, C., \& Parks, S. (2018). Child-to-child interaction during eTandem ESL-FSL chat exchanges. Language, Learning and Technology, 22(3), 176-192.

Hauck, M., \& Youngs, B. L. (2008). Telecollaboration in multimodal environments: The impact on task design and learner interaction. Computer Assisted Language Learning, 21(2), 87-124.

Helm, F. (2015). The practices and challenges of telecollaboration in higher education in Europe. Language, Learning and Technology, 19(2), 197-217. Retrieved from http://lt.msu.edu/ issues/june2015/helm.pdf.

Hyland, F. (2003). Focusing on form: Student engagement with teacher feedback. System, 31, 217-230.

Iwasaki, J., \& Oliver, R. (2003). Chat-line interaction and negative feedback. Occasional Thematic Issue of the Australian Review of Applied Linguistics (ARAL), 17, 60-73.

Jin, L. (2013). Language development and scaffolding in a Sino-American telecollaborative project. Language, Learning and Technology, 17(2), 193-219. Retrieved from http://lt.msu.edu/ issues/june2013/jin.pdf.

Kabata, K., \& Edasawa, Y. (2011). Tandem language learning through a cross-cultural keypal project. Language, Learning and Technology, 15(1), 104-121. Retrieved from http://llt.msu. edu/issues/february2011/kabataedasawa.pdf.

Kan, Q. 暤茜, Stickler, U., \& Xu, C. 徐琤 (2013). [Chinese-English eTandem learning: The role of preproject preparation and collaboration] 中英文电子搭档语言学习: 前期准备及合作协调的 作用. Chinese Language Globalisation Studies, 2(5), 1-10.

Kessler, G. (2009). Student-initiated attention to form in wiki-based collaborative writing. Language, Learning and Technology, 13(1), 79-95. Retrieved from http://llt.msu.edu/ vol13num1/kessler.pdf.

Kukulska-Hulme, A., Bossu, C., Coughlan, T., Ferguson, R., FitzGerald, E., Gaved, M., Zhang, S., ... (2021). Innovating pedagogy 2021: Open university innovation report 9. Milton Keynes: The Open University. Retrieved from https://ou-iet.cdn.prismic.io/ou-iet/4e498b2d-4ed44991-ae20-e1e0f5975cfd_innovating-pedagogy-2021.pdf.

Lee, L. (2006). A study of native and nonnative speakers' feedback and responses in SpanishAmerican networked collaborative interaction. In J. Belz, \& S. Thorne (Eds.), Internetmediated Intercultural Foreign Language Education (pp. 147-176). Boston: Heinle \& Heinle.

Lewis, T., Chanier, T., \& Youngs, B. (2011). Special issue commentary: Multilateral online exchanges for language and culture learning. Language, Learning and Technology, 15(1), 3-9.

Lewis, T., \& Peters, H. (2019). Sprachen lernen im Tandem: Prinzipien \& Kompetenzerwerb. In E. Spänkuch, T. Dittmann, B. Seeliger-Mächler, H. Peters, \& A. Buschmann-Göbels (Eds.), Lernprozesse im Tandem - ermöglichen, begleiten, erforschen. GiF:on: Giessener Fremdsprachendidaktik (13) (pp. 11-32). Giessen: University of Giessen.

Li, S. (2010). The effectiveness of corrective feedback in SLA: A meta-analysis. Language Learning, 60(2), 309-365.

Li, W. (2018). Translanguaging as a practical theory of language. Applied Linguistics, 39(1), 9-30. Retrieved from. 
Lin, C. H., Warschauer, M., \& Blake, R. (2016). Language learning through social networks: Perceptions and reality. Language, Learning and Technology, 20(1), 124-147. Retrieved from http://lt.msu.edu/issues/february2016/linwarschauerblake.pdf.

Little, D., \& Ushioda, E. (1998). Designing, implementing and evaluating a project in tandem language learning via e-mail. ReCALL, 10(1), 95-101.

Loewen, S., \& Erlam, R. (2006). Corrective feedback in the chatroom: An experimental study. Computer Assisted Language Learning, 19(1), 1-14.

Long, M. (1991). Focus on form: A design feature in language teaching methodology. In K. De Bot, R. Ginsberg, \& C. Kramsch (Eds.), Foreign language research in cross-cultural perspective. Netherlands: John Benjamins.

Long, M., \& Robinson, P. (1998). Focus on form: Theory, research and practice. In C. Doughty, \& J. Williams (Eds.), Focus on form in classroom second language acquisition (pp. 15-41). Cambridge, England: Cambridge University Press.

Luo, H., \& Yang, C. (2018). Twenty years of telecollaborative practice: Implications for teaching Chinese as a foreign language. Computer Assisted Language Learning, 31(5-6), 546-571. Retrieved from. https://www.tandfonline.com/doi/abs/10.1080/09588221.2017.1420083.

Lyster, R., \& Ranta, L. (1997). Corrective feedback and learner uptake: Negotiation of form in communicative classrooms. Studies in Second Language Acquisition, 20, 37-66.

Morris, F. (2005). Child-to-child interaction and corrective feedback in a computer mediated L2 class. Language, Learning and Technology, 9(1), 29-45.

O’Dowd, R., \& O'Rourke, B. (2019). New developments in virtual exchange for foreign language education. Language, Learning and Technology, 23(3), 1-7. http://hdl.handle.net/10125/ 44690.

O'Dowd, R., \& Ware, P. (2009). Critical issues in telecollaborative task design. Computer Assisted Language Learning, 22(2), 173-188.

Ren, S. 任仕超, \& Liang, W. 梁文霞 (2014). [An empirical study on the influence of Sino-American tandem learning on intercultural communicative competence] 中外远程协作课程对跨文化交 际能力影响的实证研究. Foreign Language World 《外语界》, 6, 87-94.

Rienties, B., Lewis, T., O'dowd, R., Rets, I., \& Rogaten, J. (2020). The impact of virtual exchange on TPACK and foreign language competence: Reviewing a large-scale implementation across 23 virtual exchanges. Computer Assisted Language Learning. Retrieved from https://www. tandfonline.com/doi/abs/10.1080/09588221.2020.1737546.

Sáez, N., \& Segovia, R. (2013). Input, interaction, and corrective feedback in L2 learning. Working Papers in TESOL and Applied Linguistics, 13, 49-51.

Sauro, S. (2009). Computer-mediated corrective feedback and the development of L2 grammar. Language, Learning and Technology, 13(1), 96-20. Retrieved from http://llt.msu.edu/ vol13num1/sauro.pdf.

Stickler, U., \& Lewis, T. (2008). Collaborative language learning strategies in an email tandem exchange. In S. Hurd, \& T. Lewis (Eds.), Language Learning Strategies in Independent Settings. Second Language Acquisition (33) (pp. 237-261). Bristol, UK: Multilingual Matters. https://doi.org/10.21832/9781847690999-015.

Tian, J., \& Wang, Y. (2010). Taking language learning outside the classroom: Learners' perspectives of eTandem learning via Skype. Innovation in Language Learning and Teaching, 4(3), 181-197.

Varnosfadrani, A., \& Basturkmen, H. (2009). The effectiveness of implicit and explicit error correction on learners' performance. System, 37, 82-98. 
Vinagre, M., \& Lera, M. (2008). The role of error correction in online exchanges. In F. Zhang, \& B. Barber (Eds.), Handbook of research on computer-enhanced language acquisition and learning (pp. 326-341). Hershey: IGI Publishing.

Vinagre, M., \& Maíllo, C. (2007). Focus on form in on-line projects: Linguistic development in e-mail tandem exchanges. In C. Periñán (Ed.), Revisiting language learning resources (pp. 91-112). Cambridge: Cambridge Scholars Publishing.

Vinagre, M., \& Muñoz, B. (2011). Computer-mediated corrective feedback and language accuracy in telecollaborative exchanges. Language, Learning and Technology, 15(1), 72-103. Retrieved from http://llt.msu.edu/issues/february2011/vinagremunoz.pdf.

Ware, P. D., \& O’Dowd, R. (2008). Peer feedback on language form in telecollaboration. Language, Learning and Technology, 12(1), 43-63. Retrieved from http://ltt.msu.edu/vol12num1/pdf/ wareodowd.pdf.

Woodin, J. (2020). From a cultural to an intercultural approach: Tandem learning and the intercultural speaker. In C. Horgues, \& C. Tardieu (Eds.), Redefining tandem language and culture learning in higher education (pp. 31-47). New York: Routledge. Chapter 2.

Wu, Z. 伍志伟 (2018). [Two decades of research on online intercultural writing exchange: Outcomes, problems, and prospects] 外语写作跨洋互动研究二十载—成果、问题与展望. Modern Foreign Languages 《现代外语》, 41, 236.

Xiong, S. 熊淑慧 (2017). [The effects of telecollaboration between Chinese EFL learners and American students on Chinese learners'English writing] 中美大学生网络远程合作对中国学 生英语写作语言特点的影响. Journal of Xi'an International Studies University 《西安外国语 大学学报》, 25, 73-78.

Xue, H. 薛红果 (2010). The impact of American students' online peer feedback on Chinese students' writing skills [网络环境下中美大学生互助交流对中国学生英语写作能力影响的实 证研究]. Foreign Language Education 《外语教学》, 31, 57-60.

\section{Bionotes}

\section{Jinlan Tang}

Beijing Foreign Studies University, Beijing, China tangjinlan@bfsu.edu.cn

Jinlan Tang is the Dean and Professor in the Institute of Online Education, Researcher at Artificial Intelligence and Human Languages Lab, Beijing Foreign Studies University, China. Her research covers the areas of language assessment, teacher training, EFL teaching and learning in the e-learning environment. She also serves as the Secretary-General of the China Computer-Assisted Language Learning Association.

\section{Kan Qian}

The Open University, Milton Keynes, UK

qian.kan@open.ac.uk

Kan Qian is Senior Lecturer in the School of Languages and Applied Linguistics, The Open University (UK). She is also Senior Fellow of the British Higher Education Academy. Her research focuses on the use of technologies for the learning and teaching of languages: mobile-assisted 
language learning, eTandem learning, and online language learning design including MOOC design.

\section{Na Wang}

Beijing Foreign Studies University, Beijing, China wangna@beiwaionline.com

$\mathrm{Na}$ Wang is a research assistant in the Institute of Online Education / Artificial Intelligence and Human Languages Lab, Beijing Foreign Studies University. She has an MA in English language education, and has been involved in online course delivery, learner support and research at the institute for more than seven years.

\section{Xiaona Hu}

Beijing Foreign Studies University, Beijing, China huxiaona@beiwaionline.com

Xiaona $\mathrm{Hu}$ is an English lecturer in the Institute of Online Education / Artificial Intelligence and Human Languages Lab, Beijing Foreign Studies University. She has an MA in English language education and has taught English for more than twelve years. She is a member of several research projects, assisting with project coordination, data collection and analysis. 